\title{
Enacting Pandemics: How Health Authorities Use the Press-And Vice Versa
}

Kristian Bjørkdabl and Benedicte Carlsen

Abstract Pandemics and other public health crises typically attract a great deal of media attention, and some scholars have argued that they are prime examples of "media hypes." That was certainly true of the 2009 pandemic, which in several countries became the biggest news story of that year. But how are pandemics mediated, and why are they mediated in that way? In this chapter, we draw on interviews with public health officials and newspaper editors in Norway, to explore how these parties co-enacted the drama that was the 2009 pandemic. We find that many of the decisions taken by the health authorities were motivated by a particular set of assumptions about how the media works, but at the same time, that the media deny the accuracy of these assumptions.

Keywords COVID-19 - Media coverage - Health officials - Mediation • Pandemic communication

K. Bjørkdahl $(\bowtie) \cdot$ B. Carlsen

Uni Research Rokkan Centre, Bergen, Norway

e-mail: kristian.bjorkdahl@sum.uio.no

B. Carlsen

e-mail: benedicte.carlsen@uib.no

(C) The Author(s) 2019

K. Bjørkdahl and B. Carlsen (eds.), Pandemics, Publics, and Politics, https://doi.org/10.1007/978-981-13-2802-2_4 
Almost invariably, pandemics and other public health crises become big news stories. We need only think of SARS, the foot-and-mouth epidemic, the tsunami disaster, the avian flu, the $2009 \mathrm{flu}$ pandemic, the Ebola epidemic, or the Zika outbreak, to understand that such episodes tend to become so-called "media hypes"-periods of intense mediation that arise whenever an issue "develop[s] a life of its own, creating huge news waves on one specific topic" (Vasterman 2005: 508; see also Vasterman 2018).

The question of why some issues become big news stories, and what that in turn means, is by no means new. In fact, this chiasmus-what causes news, and what does news in turn cause-has been a recurring object of study in journalism and media studies, with loci classici such as Galtung and Ruge's (1965) study of "news factors/values," McCombs and Shaw's (1972) study of "agenda-setting," and Downs' (1972) study of "issue-attention cycles." In much of this research, however, there has been a certain tendency to speak of news as though it were a natural phenomenon. As Stuart Hall once remarked, we often "speak of 'the news' as if events select themselves," as if the question of "which 'news angles' are most salient [is] divinely inspired" (Hall, cited in O'Neill and Harcup 2009: 163). The events that end up as news represent, however, only a tiny proportion of a great multitude, and we can only properly understand how they end up as such if we highlight the actors, institutions, and processes that make news of this small number of issues.

In fairness, there have been attempts to assimilate this way of thinking with the idea of media hypes. Wien and Elmelund-Præstekær argue, for instance, that we cannot distinguish neatly between news events and news making: "Politicians and their spin doctors know how the media work," they argue, "and they utilize this knowledge in order to get as much publicity as they can" (2009: 185). While we believe this represents a step in the right direction, it still makes news making sound like an overly mechanistic affair: If politicians know how the media work, and they utilize this knowledge in order to get what they want, the media is seen-simplistically—as a mere instrument.

In this chapter, we start from the idea that our making news of pandemics and other public health crises can usefully be viewed as a sort of drama-in other words, that the mediation of such episodes resembles the enactment of a play, for which the media functions as a stage, or even in some ways an entire theater. We take this performance metaphor 
from Stephen Hilgartner (2000), who in turn finds inspiration in Erving Goffman (1959). For our purposes, to propose that the mediation of pandemics and other public health crises can be seen as a drama is not just to say that such crises tend to be communicated as riveting plots, dotted with heroes, victims, and villains, which confront us with vertiginous climaxes and reassuring resolutions-although that does indeed tend to be the case. It is, more importantly, to place into focus the various actors and institutions responsible for enacting this drama on the media stage.

To see such crises as dramas means to see them, at least in part, as conflicts-or at the very least, as dynamic and interest-driven interactions. No actor or institution can singlehandedly stage a public health crisis, just as a play proper cannot be staged by a single person. Rather, different actors and institutions, in their different capacities, and with varying levels of expertise-not to mention divergent interests and purposes-must interact. The stage actors might not obediently follow the director's lead, however, and the director might in turn be making a soup of the playwright's intentions. Meanwhile, owners and managers keep imposing restrictions on the production, while audiences and critics remain notoriously volatile.

This combination of characteristics - on the one hand, that public health crises tend to become media hypes, and on the other, that they are dramas saturated with diverging interests-create a particular set of challenges for those tasked with responding to pandemics and other public health crises, notably the health authorities. In a modern society, pandemic response is simply not possible without the media, and if such response is to be effective, the authorities rely on getting their message across. Communication failure overlaps with a failure of pandemic response. As Jonathan Quick suggests, "health communication lies at the heart of epidemic control” (2018:22).

Not much is known, however, about how authorities attempt to use the media for their purposes during pandemics and other public health crises, nor to what extent politicians and their spin doctors actually "know how the media work." We will not be in a position to helpfully critique and correct crisis communication efforts until we understand the moves and motives of those who communicate-all those who stage the play, as it were. What is the objective of the health authorities in situations like these, and what means do they use? How, and to what extent, do the media accommodate those goals, and with what motivations? 
With the aim of understanding how authorities and media co-produced the drama that was the 2009 pandemic-officially termed $\mathrm{A}(\mathrm{HlNl})$ pdm09-we present here an interview-based study of why health authorities and media editors in Norway acted as they did during the episode. Our study reveals that the health authorities made assumptions about the media that did not match the media's own idea of what they were doing. More concretely, the health authorities were motivated by the perceived importance of "grabbing the information space," in an effort to ward off other- "inferior"-sources and messages. Media editors, however, deny the logic of this assumption. We find, in other words, that the various actors involved in the co-production of this play had somewhat different conceptions of the production at hand, and we stipulate that this might have left the audience rather confused about what the play was really about (for more on the audience response, see Bjørkdahl and Carlsen 2018).

\section{Minor Pandemic, Major Response}

The mediation of the flu began on April 25, 2009, the day after the World Health Organization (WHO) had issued a worldwide Disease Outbreak Notice, declaring that a new influenza had been detected in Mexico. Epidemiologists expect flu pandemics to occur with a certain interval, and after the Avian flu outbreak of 2005 had not reached pandemic scales, public health officials were by 2009 anxiously anticipating the next one. When news arrived from Mexico, the WHO's response was thus swift and forceful. A "public health emergency of international concern" was declared, and the pandemic alert level was raised, first from 3 to 4 , and then from 4 to 5 , by April 29. On June 11, it was raised again, to Level 6 , which meant that a pandemic was declared (CDC 2010). The WHO's lead was quickly followed up by the various national health authorities, who turned to their respective populations with information and advice-in general by way of the media. In Norway, from where we draw our material, the health authorities informed the public through press conferences, daily reports and press releases, participation in radio, press, and TV interviews and debates, op-eds in the newspapers, as well as their own website, pandemi.no (see Chapter 6 of this volume). With a few exceptions, communication about the pandemic in Norway resembled that in many other countries (see Carlsen and Glenton 2016). 
On Monday 27 April, only a few days after news about the flu first broke, the Norwegian health authorities entered the scene with a major press conference featuring the main health authorities involved. Press conferences are rare events in Norwegian public health work, and this one was quite exceptional. It took place in a large venue in "Regjeringskvartalet," the government quarter, was live streamed, and contained somber presentations by the Minister of Health, the Health Director (i.e. the chief public health bureaucrat), and an epidemiological expert at the National Institute of Public Health. The representative of the Institute and the Health Director both emphasized the uncertain state of the knowledge about the disease, but the latter in addition informed the public of a "worst case" scenario which was embedded in Norway's official pandemic plan. This scenario estimated that 1.2 million Norwegians-roughly a quarter of the country's population at the time-could be contaminated by the disease and that as many as 13,000 Norwegians might die. Accompanying this message were images on a big screen of health workers in protective gear, who appeared to be placing a corpse in a coffin.

This set off a veritable flood of news coverage, which continued, in three main waves, throughout 2009. During the duration of the pandemic, the coverage spanned more or less all sorts of news genres, latching the flu onto a great variety of other stories-from the preparedness of hospitals, to the risk of contamination during a major football tournament, to new hand-cleaning practices in schools and kindergartens, and so on. The coverage as a whole did not leave out critical voices, and a great deal of the authorities' communication consisted in responding to complaints and criticisms. "The health authorities" denotes here Ministry of Health and Care Services, the Directorate of Health, an executive and regulatory agency charged with enacting public health policy, and the Norwegian Institute of Public Health, which is primarily a research institution, but which has increasingly taken on a mandate of research communication, recommendations, and science advice. Norway being a small country, these governmental agencies are very tight-knit, and had as their stated goal to speak with one voice during the pandemic. The news media landscape is rather more diverse, and consists of largely depoliticized party presses that span from tabloids, such as Verdens Gang and Dagbladet to more serious outlets like Aftenposten and Dagens Neringsliv, in addition to a great number of local newspapers and radio stations.

For the present study, we have interviewed 6 media editors and 12 representatives of the health authorities, the majority of interviews 
lasting approximately an hour. The selection of media was somewhat random, but did include both tabloid and reputable outlets, both nationally and regionally. The selection of health authorities is more complete, and includes interviews with the heads of the relevant agencies, their deputies, as well as communication officers and senior researchers. In the case of the editors, all but one were interviewed twice, at the beginning and towards the end of our project. The representatives of the health authorities were interviewed only once, but some were followed up via e-mail.

\section{Grabbing the “Information Space”-With GRaVitas}

In our interviews, it quickly transpired that the health authorities' communication efforts during the pandemic had sprung from a communications strategy that was widely shared among all the relevant agencies. In essence, the strategy rested on an assumption that the authorities should communicate openly and at an early stage, in order to "grab the information space," as several of our informants put it. The authorities believed that by "filling" the media with messages they considered desirable, they would "crowd out" other, less reliable, sources of information. In practice, this objective was combined with the decision to communicate very solemnly-one might even say gravely-about the disease. This consideration rested on the assumption that if they did not communicate with sufficient seriousness, they could face an even more somber scenario later, if the disease turned out to be serious. It was better to "push the big button," as the Ministry's secretary general said, even if that meant one had to "tone things down afterwards." She added, "I would rather face criticism for being too dramatic than for being too undramatic" (Al). The Minister said almost precisely the same thing: "I would rather be criticized for exaggerating this, if it turned out not to be that bad, than be criticized for minimizing it if it was bad" (A2). The Director of Health likewise stated, "You can't risk the attitude that it probably isn't serious" (A5).

If this, by 2009 , had become the general attitude among the health authorities, a research director at the Institute of Public Health explained that the imperative to communicate openly and at an early stage reflected quite recent changes in her institution's approach to public communication. "In the old days, our director did most [of our communication]," she said, and explained that they, just a few decades ago, had been far 
more reserved in their approach to the media. In the last 15 years or so, she explained, "we have grown aware that since everything gets out anyway, better that it should come from us than from some other party and this probably describes our thinking in 2009" (A3).

The Institute's spokesperson emphasized the same point, noting that 20 years ago, "certain reports would be marked 'Not to be published except with the approval of...' Now, however, it is important to get as much information as we can out there, as fast as we can, quality-controlled as well as we can in the short time we have available." $\mathrm{He}$ said that this new "proactive relation to the media" represented a "total turnaround in this area," and added that, "When the pandemic came, this was the kind of thinking we had in our spines, that we ought to tell them what we know" (A4).

Occasionally, this communicative imperative was connected to civic ideals like transparency, knowledge-sharing, etc., but as a rule, our informants justified it strategically. To communicate openly and at an early stage would quite simply yield better results; it would put the authorities in a better position. "There is always someone who knows," the research director noted, "and [the media] can easily get a hold of someone with an opinion. Not to mention that news travels very fast" (A3). Then she added the phrase that recurred in most all of our interviews with the health authorities: "If we don't grab the information space there will always be someone else there to do it" (A3).

She motivated this by saying that the health authorities might, at a later stage, find themselves in a situation "where we are asked to explain and defend ourselves" and that would be a much easier task, she said, if they did not have to "try to change a picture that someone has already created" (A3). In other words, she emphasized the importance of the power of definition: Only by getting on the media stage early, with seriousness but without pretense, could they be the ones to define what this disease was all about. If the pandemic is seen as a drama, we have found an assumption that one needs to put one's own stamp on the production, quickly and firmly, before someone else comes along and does precisely that.

The Health Director rehearsed the same message in justifying the decision to organize the first press conference: "If you don't grab the information space, there will in any case be a lot of information out there, but other sources will be providing that information." He used a similar logic when justifying their practice of frequent press briefs. Had they not held these briefs, the media coverage would have been 
dominated by views with which the health authorities strongly disagreed, he said, and added that "the press briefs guarantee that we, who after all command a system that can actually understand the situation, are the media's most important informants" (A5).

The announcement of the infamous worst-case scenario was justified with reference to a similar rationale. Since that scenario could already be found in public documents, the director noted, a pre-emptive move was the only sensible one. "The media would no doubt get their hands on it - and this much we know, that if the media finds stuff like this, there will be a story" (A5). His words were echoed by his assistant director of communications, who said that, "if we hadn't informed the public what we had planned for, someone would have figured it out" (A6). The Ministry's secretary general made even more clear the dangers of not communicating openly and at an early stage: "Had we not done that, the next story would have been: "Here is what the Ministry is hiding"' (Al).

The authorities assumed, in other words, that the media would be "digging for dirt" - that their first impulse would be to sniff out a scandal or instance of misconduct that would play well on the front page. This assumption appears to have taken a firm hold of our informants, which meant, among other things, that they reflexively converted their communications strategy into an evaluative statement after-the-fact. The secretary general referred, for instance, to "all those on the outside who wanted big stories on some special interest issues connected to the pandemic," and argued, as though she were describing what had actually happened, that, "Because we filled the space with what we had of professional knowledge, it was harder for them to get their messages across, and only those who really had a solid message really got across, or had an impact" (Al).

What would have happened had the authorities not chosen this strategy, we cannot know. But it is certainly the case that Norwegian media, at least after a while, came to be filled with all sorts of messages and "special interests." In fact, the media coverage of the pandemic allowed not just for the authorities' own "professional knowledge," but also for various criticisms, coming from actors in many different capacities, including doctors and professors of medical ethics and social medicine, all the way to outright conspiracy theories, which held that the disease and/or the vaccine was a conspiracy enacted by an unholy alliance between Big Pharma, the $\mathrm{WHO}$, and our national health authorities. 
Nevertheless, there is no doubt that the imperative described above was in fact what motivated the authorities' communication during the pandemic, that this imperative was felt across the various agencies involved in handling the pandemic; and that they all justified it primarily with reference to strategic concerns. In our efforts to find out why this imperative had come to form such a hard core in the authorities' communications strategy - to the extent, in fact, that none of our informants saw any reason to correct it after the experience from 2009-three main factors came to light:

The first has to do with a general change in how all of these institutions approached public communication, which might in turn have to do with an even more general change in society as such. As our informants explained, there was a sense that one ought now to communicate more, more often, more willingly, sooner, and more "openly," which is to say, more transparently than one had in the past. In part, this was seen simply as a given, as an imperative that had emerged in the course of the last few decades. A few informants related it to changes in the journalistic field. They suggested that news media over time had been growing increasingly short on resources, and that reporters consequently had to dig out more "scandals" at a lesser cost, a development some of our informants connected to a general increase in the "pace" of news. In short, news moves faster than it used to, therefore the authorities have to do so as well.

The second factor had to do with a small number of concrete episodes, where the most influential people in the Norwegian health authorities felt they had made insights about "how the media work," as Wien and Elmelund-Præstekær put it. One particularly notable episode was the 2004 tsunami disaster, which befell a notable number of Norwegian tourists vacationing in Thailand, and which was handled poorly by the Norwegian government. "We were blindsided by it," said the secretary general at the Ministry (Al). That entailed a shift towards establishing a more proactive attitude to preparedness, to make sure that plans (which had existed also in 2004), were "alive," and then, in an attempt to succeed with the first goal, to knit the different governmental entities in the health sector more tightly together, so that they would speak with one voice and act as one body when the time came. We understand this effort to be one important reason why most all our informants in the health authorities use literally the same language when speaking about the 2009 response. 
Finally, a third factor was theory. According to the assistant communications director at the Directorate, "We have based our work on a theoretician called Peter Sandman, and there is one staffer in particular who has driven forth this way of thinking in our department" (A6). She emphasized that they did not "work strictly according to a theory," but then went on to explain how their communication strategy during the pandemic was in fact in line with Sandman's theories: "What's special about [Sandman] is that he is very clear that you should not hold back on anything, and not try to hide anything, and that was the background for our being very clear about what we have prepared for, what we have planned, what kind of scenarios we envisioned, the best and the worst" (A6). Whatever the precise relation between communication theory and practice in these institutions, the fact that they were so explicitly aware that "their" strategy had been elaborated and defended in an academic context is likely to have consolidated their faith in it.

\section{First We Forward Information, Then We Criticize the Source}

If this sums up some of the assumptions of one central group of actors involved in staging the 2009 pandemic, we turn now to another group who were important in that production: the media. Although the media editors' perspective was certainly not wholly different from what we found among the representatives of the health authorities, they did depart from the latter in some significant, and perhaps surprising, ways.

Our informants in the media said, very uniformly, that the main reason why the pandemic became such a big story, both in quantitative terms and in terms of the journalistic rhetoric, was the authorities' "drum-banging," in particular the infamous first press conference. When the authorities make a move like that, the editors explained, it would be almost irresponsible for news media not to "go big." The concern to convey "information" from the authorities, is one of several functions of the media in a situation like this, they pointed out. Another is criticism, which here meant to investigate the background for the advice given, find sources that had another take on the situation than the one presented by the authorities, and so on. The editors, however, point to certain practically inevitable conditions which impose a chronological order on these functions - in short, the critical function can only be performed after a while. The media themselves have no competence to make independent 
assessments on issues such as pandemics, and they also typically lack access to other good sources in the initial phase. Indeed, the editors explain that it is equally necessary for them to lean on the authorities in the first phase as it is to lean on a wider set of sources in the following one.

"We see it as the role of the media generally to convey central and important warnings issued from the authorities to the public," said one editor, but added that "another concern is to examine the authorities' exercise of power, which entails looking into what grounds they have to offer the advice they give the population" (M4). While most all the editors we interviewed touched on both of these two purposesinformation and critique - they all also emphasized that the most important one, chronologically speaking, was the former.

They had several explanations why this was so. The first of them was an obligation of their occupation, which meant that they had no real choice about what to do after the first press conference. "The swine $\mathrm{flu}$ is a good example of an issue where the authorities struck a solemn chord from the very start," said one, and explained that, "It was pretty obvious that we were going to make this a priority ... when heavy actors like these ... including the Minister of Health come on the scene so strongly" (M4). The first press conference was in fact highlighted by all the editors as a highly significant event: "The turning point for us was that big press conference, where we understood that the authorities are taking this very seriously, and we were taken by this kind of duty to inform the public and be serious about our coverage of the issue" (M2). Another said that, "What took hold at our paper was a strong obligation to inform the public." The same editor explained that reflex as a practical expression of a general value of journalism: "This is a very strong desire in a situation where the whole population is under threat that the issue is: How we can inform in a proper way" (M3). One editor elaborated this point, saying that the first press conference set off the information reflex of the media: "When the authorities sound a national epidemics alarm, and present the kinds of scenarios they did in this case, they bring a certain gravity to the situation; it is made into a national matter, and for that reason the alarm goes off in the media" (Ml). As they explained, the media's reaction to the first press conference was a duty of information, an obligation to "inform in a proper way." Given the gravitas with which the authorities first announced this new flu, the media coverage that ensued was simply a case of the media taking the authorities' seriousness seriously. 
At the same time, the editors are keen to point out that this kind of "forwarding" of information from the authorities is just one of their two main functions, and that these two typically follow a certain order. As one editor lamented, "ideally, we should be doing both [information and critique] at the same time, but what typically happens in practiceand this is my experience after 20 years in this game-is that we, in a first, acute phase tend to simply forward what is communicated" (M4). She acknowledged that this might be the case particularly in small news organizations like her own, but based on experience from other, larger news media, insisted that it was a general trend: First, one forwards the authorities' message, in "informational" form; then, one gets down to questioning and criticizing it. One editor referred to this equation as "a sort of built-in dramaturgy," and as "classical news journalism": "First, you write about it, then in the next phase, you place the authorities under close scrutiny" (M3).

This explanation was repeated, with only minor alterations, by all the rest of the editors we interviewed. Although they sometimes referred to this dynamic almost as a natural fact, what they meant was that it was a product of the incentives that are typically at play in the newsroom. Limited resources means one simply lacks the manpower to fulfill both functions at the same time, at least not from the start. This is particularly impossible, the editors pointed out, with technical issues like a pandemic, since only very few news organizations employ designated health journalists with the competence to raise critical questions from the start. As one editor pointed out, "Most newspaper don't possess the competence among their in-house staff to assess whether the information provided by experts about a disease like this is accurate or not. We don't even have a designated health journalist!" (M5). Another said that, "I don't have the medical knowledge to judge whether what is said is correct or not" (M4).

The typical consequence of this is, again, that the media-especially in the first phase of the coverage-have no choice but to rely heavily on the official sources, in this case, the health authorities. "It's not so easy to be critical in this phase," said one editor, "because we don't have sources besides the authorities themselves. Later, obviously, other sources enter the picture, and the critical stance becomes more important" (M3). One editor argued that this should give no cause for concern, as "the authorities are, generally, very good sources. I mean, they have the expertise, and they are supposed to have that expertise, and for that reason alone, they are an obvious source for us" (M5). 
There is in other words both a push and a pull here, both a practical reason and a professional one: News media on the one hand must rely on official sources in this first phase, but they also feel an obligation to do so. When important societal actors like the health authorities get on the stage-as they literally did during the above-mentioned press conference-the media feel obligated by the norms of their profession to report. As one editor stated, "In retrospect one might suggest that we ought to have problematized the authorities' alarm, but this is not so obvious; should we, from day one, or two or three or four, when the authorities used this kind of weaponry, not have reacted with gravity?" (Ml). The same informant added that, although the first phase of coverage of the flu was a story "on the authorities' terms," it would not be relevant to criticize the media for being a mere mouthpiece to the government. Rather, he argued, "when there is this type of alarm, it is our job to contribute to informing the public in a broad way" ( $\mathrm{Ml})$.

But just as it is part of the professional ethics of journalists to report "broadly" and forward the authorities' information, another part is to bring critical perspectives: "It is your job to balance, to draw up appropriate dimensions and introduce other voices, and to ask critical questions" (Ml). All the editors underlined, however, that this function came only later. This again was explained with reference both to a professional value and to the incentives of the newsroom: On the one hand, it is a central part of journalism to question the authorities, on the other, "it is in the nature of news," as one informant said, "that it is no longer news if you keep reporting the same thing" (M4). News journalism, she added, "keeps looking for new angles, whether it's an improvement or a deterioration of the issue you have presented, or whether new aspects come up that might be interesting" (M4). So while the critical function was partly motivated by the journalistic obligation to hold the authorities accountable, another motivation, again, was resources. As the same editor explained, "For a small newspaper like ours, a serialized story like this makes good sense. To grab hold of a small number of issues, that's a good method for us, first because it allows us to create a [narrative] in a violent storm of information, but also because we can create a sense of in-depth knowledge on particular issues" (M4). In other words, the function to dig for dirt and come up with criticism is-just as the function of information-not just one of journalistic ideals, but also one of journalistic finances. 


\section{Working Out How the Media Work}

The most important finding from these interviews, we believe, is that the health authorities and the media made quite different assumptions about how pandemics and other public health crises are enacted on the media's stage. In an attempt to be the playwrights of this drama, the authorities put great emphasis on going to the media at an early stage and to communicate broadly and openly-not "holding back on" or "trying to hide" anything, just as their preferred theoretician prescribed. This priority reveals, however, that the authorities-contra the pronouncement of Wien and Elmelund-Præstekær-do not necessarily "know how the media work."

In fact, the authorities' notion that "grabbing the information space" was a prerequisite for getting their message across, appears quite simply to be wrong. As the editors explain, they do not have the resources to question the authorities in this first phase, and hence, there is not necessarily a need to rush things. In technical issues like a pandemic, the media is going to want to hear the authorities' story anyway. Despite their reputation for always sniffing out a scandal-for always wanting, as the Institute's research director said, "something, anything, that can create a headline" (A3) - the media consider it their professional duty to forward the authorities' information in grave situations like a pandemic. The media count the authorities to be not just the first, but also the best, source on the matters such as these, and this insight could, we imagine, cause the authorities to readjust their communication strategy. Instead of communicate openly and at an early stage, one could perhaps consider communicate honestly and at the appropriate time?

The other aspect of the authorities' assumption appears to be equally wrong: Their decision to communicate openly and from an early stage did little to "ward off" other sources. In fact, despite the demonstrably important and in many ways unprecedented first press conference, not to mention the authorities' frequent press briefs, the media after a while did move on to using a wider set of sources, many of which were critical of the official health apparatus. Also, the media themselves - via its columnists, editorials, editorial choices of angles, etc.-increasingly cast a more critical light on the authorities' pandemic response and communication. According to the editors, this had little to do with this pandemic's particular course, but was rather an almost inevitable effect of the incentives at play in the newsroom-a "sort of built-in dramaturgy," as one editor 
put it. News media cannot keep running the same story with the same angle over time, because if they did, they would no longer be conveyors of news. Given the concrete incentives of a newsroom, then, they must do one of three things: Write the authorities' angle, write someone else's angle, or find a new story altogether.

It is thus our conclusion that the authorities in this case relied on a communication strategy that, in some important ways, did not understand "how the media work." Had they more profoundly taken into account the incentives of the newsroom, the authorities could probably have prevented the overly dramatic first wave of coverage, which was almost certainly a direct effect of their press conference. They could consequently have averted the need to backtrack, which arguably created a certain confusion as to the severity of the disease (Bjørkdahl and Carlsen 2017). They could, quite simply, have managed to stage a drama that was closer to their own vision.

\section{REFERENCES}

Bjørkdahl, Kristian, and Benedicte Carlsen. 2017. Fear of the Fear of the Flu: Assumptions About Media Effects in the 2009 Pandemic. Science Communication 39 (3): 358-381.

Bjørkdahl, Kristian, and Benedicte Carlsen. 2018. Pandemic Rhetoric and Public Memory: What People (Don't) Remember from the 2009 Swine Flu. In Rhetorical Audience Studies and Reception of Rhetoric: Exploring Audiences Empirically, ed. Jens Kjeldsen, 261-284. London: Palgrave Macmillan.

Carlsen, Benedicte, and Claire Glenton. 2016. The Swine Flu Vaccine, Public Attitudes, and Researcher Interpretations: A Systematic Review of Qualitative Research. BMC Health Services Research 16: 203.

CDC (Centers for Disease Control and Prevention). 2010. The $2009 \mathrm{HINl}$ Pandemic: Summary Highlights, April 2009-April 2010. https://www.cdc. gov/hlnlflu/cdcresponse.htm.

Downs, Anthony. 1972. Up and Down with Ecology: The Issue-Attention Cycle. Public Interest 28: 38-50.

Galtung, Johan, and Mari Holmboe Ruge. 1965. The Structure of Foreign News. The Presentation of the Congo, Cuba, and Cyprus Crises in Four Norwegian Newspapers. Journal of Peace Research 2 (1): 64-91.

Goffman, Erving. 1959. The Presentation of Self in Everyday Life. New York: Anchor Books.

Hall, Stuart. 1973. The Determinations of News Photographs. In The Manufacture of News: Deviance, Social Problems and the Mass Media, ed. Stanley Cohen and Jock Young, 226-243. London: Constable. 
Hilgartner, Stephen. 2000. Science on Stage: Expert Advice as Public Drama. Stanford: Stanford University Press.

McCombs, Maxwell, and Donald Shaw. 1972. The Agenda-Setting Function of Mass Media. The Public Opinion Quarterly 36 (2): 176-187.

O'Neill, Deirdre, and Tony Harcup. 2009. News Values and Selectivity. In The Handbook of Journalism Studies, ed. Karin Wahl-Jorgensen and Thomas Hanitzsch, 161-174. New York: Routledge.

Quick, Jonathan. 2018. The End of Epidemics: The Looming Threat to Humanity and How to Stop It. New York: St. Martin's Press.

Vasterman, Peter. 2005. Media-Hype: Self-Reinforcing News Waves, Journalistic Standards and the Construction of Social Problems. European Journal of Communication 20 (4): 508-530.

Vasterman, Peter. 2018. Introduction. In From Media Hype to Twitter Storm: News Explosions and Their Impact on Issues, Crises, and Public Opinion, ed. Peter Vasterman, 17-38. Amsterdam: Amsterdam University Press.

Wien, Charlotte, and Christian Elmelund-Præstekær. 2009. An Anatomy of Media Hypes: Developing a Model for the Dynamics and Structure of Intense Media Coverage of Single Issues. European Journal of Communication 24 (2): 183-201. 